Original article

\title{
Epidemiology of generalized ligamentous laxity in northwest of Iran: A pilot national study on 17-40 years old adults in Hamadan province
}

\author{
Hossein Saremi $^{\mathrm{a}, *}$, Farnaz Shahbazi ${ }^{\mathrm{b}}$, Amir Hossein Rahighi ${ }^{\mathrm{b}}$ \\ ${ }^{a}$ Department of Orthopedic Surgery, Hamadan University of Medical Sciences, Hamadan, Iran \\ ${ }^{\mathrm{b}}$ Students Research Center, Hamadan University of Medical Sciences, Hamadan, Iran
}

\section{A R T I C L E I N F O}

\section{Keywords:}

Generalized ligamentous laxity

Beighton score

Epidemiology

Iran

Ethnicity

\begin{abstract}
A B S T R A C T
Background: Many people suffer from ligamentous laxity even in the absence of other diseases. This is called the benign generalized ligamentous laxity. It can be a predisposing factor for musculoskeletal and joint injuries. We did this research to determine the prevalence of generalized ligamentous laxity in different ethnic groups of Hamadan province as a pilot study for a future national investigation.

Materials and methods: In this descriptive-analytical study, 378 people were selected by simple sampling in 2017 from a province in northwest of Iran. We looked for the ligamentous laxity in them with clinical examination according to Beighton's score criteria using goniometer for measuring the joint movement's angle. The population included people between 17 and 40 years old. They were from various Iranian ethnic backgrounds who were living in this province.

Results: Eighty-six participants (22.8\%) had generalized ligamentous laxity. Generalized ligamentous laxity was more prevalent in women (31.5\% compared to $14.7 \%$ in men). The most common ligament laxity was on the fingers. Most participants with generalized ligamentous laxity (78 of 86 participants) had no knowledge of their problem and its importance in choosing the appropriate sports activities; 12 of 86 participants (14\%) had a history of sports-related injuries, and 31 of 86 participants (36.5\%) had a musculoskeletal disease.

Conclusion: The prevalence of generalized ligamentous laxity is considerably higher in women regardless of their ethnicity. Most people are unaware of their problem. Also, the history of musculoskeletal diseases is significantly higher in people with this problem compared to those without it.
\end{abstract}

\section{Background}

Ligamentous laxity is defined as the excessive movement of the joints. ${ }^{1}$ In ligamentous laxity, the joints' range of motion is more than the defined normal range of movement. ${ }^{2}$ The prevalence of physiological hypermobility of ligaments is higher in girls than boys, ${ }^{2}$ which may be because of hormonal factors. In most cases, the hypermobility of the joints has been present since birth, but its diagnosis can be delayed until childhood, adolescence and even adulthood. This condition may increase the elasticity of the affected joints with an impact on the limbs and axillary joints. ${ }^{3}$ Also, it is known to be present in some collagen disorders, such as Ehlers Danlos, Marfan syndrome and Osteogenic Imperfecta. ${ }^{3-5}$ It is also seen in many healthy people in the absence of other diseases, which is referred to as the benign hypermotility joint syndrome. ${ }^{6,7}$

The incidence of generalized ligamentous laxity is about five times higher in women compared to men. ${ }^{8}$ Ligamentous laxity results in joints' excessive movements and it is associated with the connective tissue disorder. ${ }^{9}$ People with generalized ligamentous laxity may have no problem, but joint laxity can be a predisposing factor for all types of musculoskeletal disorders including ligamentous injuries and instability. ${ }^{10}$ Ligamentous laxity occurs in $4 \%-13 \%$ of people without any systemic or rheumatologic diseases. ${ }^{11,12}$ It is associated with musculoskeletal injuries, such as knee cruciate ligaments injuries, ankle sprain, and shoulder instability. ${ }^{13,14}$ Ligamentous laxity is an important predisposing factor in athletes with shoulder injuries and instability. ${ }^{15}$

Therefore, studying the joint laxity and possible presence of "generalized ligamentous laxity" will make people aware of this problem. It can put forward pre-screening methods for schools and sports clubs to help people choose an appropriate sports activity and prevent musculoskeletal and sports injuries. To the authors' knowledge, no study has investigated the role of generalized ligamentous laxity and its prevalence in an Iranian adult population with different ethnic backgrounds. Thus, we investigated the prevalence of the generalized

\footnotetext{
* Corresponding author. No 40, Noor St, Mokhtaran Ave, Saidi Boulevard, Hamadan, 6515699151, Iran.

E-mail address: hosseinsaremi.shoulder@gmail.com (H. Saremi).
} 
ligamentous laxity on adults from various ethnic groups who lived in a northwestern province of Iran to achieve valuable information for preventing musculoskeletal and sports injuries.

This was a pilot study for evaluating generalized ligamentous laxity in different ethnic groups of Hamedan province in Iran. We are planning to do a nation-wide study of generalized ligamentous laxity in young population of the country with the help of six medical universities in different parts of Iran.

\section{Methods}

This descriptive-analytical study was done on people, aged 17-40 years old, who were living in the Hamadan province, located in northwest of Iran. The participants were chosen with simple sampling. We chose nearly $50 \%$ of the participants of each ethnicity from men and the rest from women.

\subsection{Study participants}

The sampling sites included high schools, universities and sports clubs. Our study had four sub-groups based on ethnicity: Azeri, Lur, Persian and Kurdish. For our Azeri ethnic group, we chose from people who had originally came from other cities of Iran in which most of the population are of Azeri (Persian-Turkish) ethnicity (they themselves and both their parents were of those cities). For our Lur ethnic group, we chose people from Nahavand city in which most people are considered to be of Lur origin (they themselves and both their parents were of this city). For our Persian ethnic group, we chose people whose background was from Hamadan city in which most people are considered to be of Persian origin (they themselves and both their parents were of this city). For our Kurdish ethnic group, we chose people from among those who had immigrated from Kurdistan province of Iran and were living in Hamadan province (they themselves and both their parents were from Kurdistan province).

The selected participants were clinically examined. Their demographic characteristics were collected by a questionnaire. The clinical examination was carried out with a goniometer and evaluated using the Beighton's scoring system (Table 1).

\subsection{Inclusion and exclusion criteria}

The inclusion criteria were: 1 ) being $17-40$ years old; 2) having two normal upper and lower extremities (without any amputation); 3) not having congenital or acquired problems in their upper and lower extremities, spinal cord and vertebral column; 4) both parents and the person him/herself were born in the same place from which we chose the participants of a particular ethnicity; and 5) completing the questionnaire and undergoing all the examinations.

Any individual who withdrew from the study or refused to complete the questionnaire and undergo clinical examinations was excluded from

\section{Table 1}

Beighton score to assess generalized ligamentous laxity.

\begin{tabular}{lll}
\hline Joint & Evaluation & Points \\
\hline $\begin{array}{l}\text { Left little (5th) finger } \\
\text { Right little (5th) finger }\end{array}$ & $\begin{array}{l}\text { Passive dorsiflexion }>90^{\circ} \\
\text { Passive dorsiflexion }>90^{\circ} \\
\text { Peft thumb }\end{array}$ & 1 \\
& $\begin{array}{l}\text { Passive dorsiflexion to the flexor aspect of } \\
\text { the forearm }\end{array}$ & 1 \\
Right thumb & $\begin{array}{l}\text { Passive dorsiflexion to the flexor aspect of } \\
\text { the forearm }\end{array}$ & 1 \\
Left elbow & $\begin{array}{l}\text { Hyperextension }>10^{\circ} \\
\text { Right elbow }\end{array}$ & $\begin{array}{l}\text { Hyperextension }>10^{\circ} \\
\text { Left knee }\end{array}$ \\
$\begin{array}{l}\text { Right knee } \\
\text { Forward flexion of the } \\
\text { trunk with knees }\end{array}$ & $\begin{array}{l}\text { Hyperextension }>10^{\circ} \\
\text { Fully extended, able to rest palm and hands } \\
\text { flat on the floor }\end{array}$ & 1 \\
\hline
\end{tabular}

the study.

\subsection{Statistical analysis}

Descriptive information was summarized in the form of tables, charts, and measures of central tendency and dispersion. Chi-square test was used to compare the frequency of ligamentous laxity by gender and ethnicity. The $t$-test was used to compare the frequency of ligamentous laxity by age. The significance level in this research was 0.05 . The statistical population was the total population aged 17-40 years old in Hamadan province in 2017. The collected data were analyzed by statistical package for the social science (SPSS) software version 16. The confidence level was $95 \%$.

\subsection{Calculation method}

\begin{tabular}{lll}
\hline $\mathrm{P}$ & 0.27 & $n=\frac{(z 1-\alpha / 2)^{2} \cdot P(1-P)}{d^{2}}$ \\
$\mathrm{Q}$ & 0.73 & \\
$\alpha$ & 0.05 & \\
$\mathrm{D}$ & 0.05 & \\
$\mathrm{~N}$ & 300 & \\
\hline
\end{tabular}

The p-number of ligamentous laxity prevalence was selected from a reference number. ${ }^{12}$ In our study, the alpha value and $\mathrm{d}$ (standard error) were both considered at 0.05 . The sample size was estimated to be 300 individuals based on the formula. However, we chose 378 people to cover possible exclusions.

The diagnosis of ligamentous laxity was based on the clinical evaluation system of Beighton and Horn. Beighton's scoring system is a more common method for detecting ligamentous laxity. In this scoring system, scores of 4 and more indicate a ligamentous laxity. ${ }^{9}$

\subsection{Ethical considerations}

The questionnaires were anonymous, and the information was reported confidentially in the form of tables and charts. An informed consent from was signed by each participant older than 18 years old. For those who were between 17 and 18 years old, the informed consent was signed by their parents too. This study was approved by the ethics committee of our university (IR.UMSHA.REC.1394.20).

\section{Results}

A total number of 378 people were studied: 197 (52.1\%) were men and $181(47.9 \%)$ were women. Their mean of age was $25.34 \pm 7.82$ years old (17-40 years old). The first quartile was 19 years old, mid 24 years old, and the third quartile was 30 years old. Regarding ethnicity, $101(26.72 \%)$ participants were Persian, 97 (25.66\%) were Azeri, 95 (25.13\%) were Kurdish and 85 (22.49\%) were Lur.

The most common ligamentous laxities were in the left thumb (29.1\%), left small finger (28.3\%), right thumb $(27.8 \%)$ and right small finger (27.0\%), respectively. 86 (22.8\%) participants had ligamentous laxity (Beighton's score of 4 and above) (Table 2). 147 participants did sports activities. Football (10.3\%), volleyball (5.6\%) and body building (74.4\%) were the most common sports activities, respectively. The average of exercise period in those who had a history of an exercise was $4.46 \pm 2.80$ years (1-15 years; Table 3$)$.

From among 378 participants, $63(16.7 \%)$ had a history of musculoskeletal problems, and $315(83.3 \%)$ had no history of any disease (Table 4). Some people had more than one problem. According to the Chi-square test, the percentage of musculoskeletal disorders in participants with generalized ligamentous laxity was significantly higher than non-affected participants $(36 \%$ vs. $11 \%)(P<0.001$; Table 5$)$. The prevalence of generalized ligamentous laxity was significantly lower in men compared to women. The mean age of those who had ligamentous 
Table 2

The frequency of ligamentous laxity according to the Beighton's scoring system.

\begin{tabular}{llll}
\hline Joint & Criteria & Total & Percentage \\
\hline Left little finger & Passive dorsiflexion more than $90^{\circ}$ & 107 & 28.3 \\
Right little finger & Passive dorsiflexion more than $90^{\circ}$ & 201 & 27.0 \\
Left thumb & $\begin{array}{l}\text { Passive dorsiflexion up to the forearm } \\
\text { flexor level }\end{array}$ & 110 & 29.1 \\
& Passive dorsiflexion up to the forearm & 105 & 27.8 \\
Right thumb & flexor level & & \\
& Hyperextension more than $10^{\circ}$ & 27 & 7.1 \\
Left elbow & Hyperextension more than $10^{\circ}$ & 25 & 6.6 \\
Right elbow & Hyperextension more than $10^{\circ}$ & 10 & 2.6 \\
Left knee & Hyperextension more than $10^{\circ}$ & 13 & 3.4 \\
Right knee & By bending the trunk forward and full & 83 & 22.0 \\
Trunk bending & extension of the knees, palms can touch & & \\
\multicolumn{1}{c}{ forward } & the ground & & \\
& & &
\end{tabular}

Table 3

The frequency of physical activities and sports.

\begin{tabular}{lll}
\hline Physical activity & Frequency (\%) & Sports \\
\hline Yes & Football & $39(10.3)$ \\
& Volleyball & $21(5.6)$ \\
& Bodybuilding and Fitness & $18(4.76)$ \\
& Taekwondo & $11(2.91)$ \\
& Basketball & $10(2.64)$ \\
& Karate & $9(2.38)$ \\
& Wrestling & $7(1.85)$ \\
& Swimming & $6(1.58)$ \\
& Handball & $5(1.32)$ \\
& Running & $5(1.32)$ \\
No & Other sports & $16(4.23)$ \\
Total & & $231(61.1)$ \\
& & $378(100)$ \\
\hline
\end{tabular}

${ }^{\text {a }}$ Cycling, Kung Fu, Judo, Hockey, Rock Climbing, Self-defense, Skating.

Table 4

The frequency of history of musculoskeletal disorders in the studied participants.

\begin{tabular}{lll}
\hline $\begin{array}{l}\text { History of musculoskeletal } \\
\text { disorders }\end{array}$ & Type of disorder & Frequency (\%) \\
\hline Yes & $\begin{array}{l}\text { Lateral or medial deviation } \\
\text { of the legs }\end{array}$ & $24(6.35)$ \\
& Chronic joint pain & $22(5.82)$ \\
& Joint dislocation & $14(3.70)$ \\
& Flat foot & $9(2.38)$ \\
& Spinal deformity & $22(0.52)$ \\
No & & $315(83.3)$ \\
Total & & $378(100)$
\end{tabular}

Table 5

The frequency of musculoskeletal disorders concomitant with generalized ligamentous laxity.

\begin{tabular}{llll}
\hline History of musculoskeletal disorders & \multicolumn{2}{l}{ Ligamentous laxity } & \multirow{2}{*}{ P value } \\
\cline { 2 - 3 } & Yes (\%) & No (\%) & \\
\hline Yes & $31(36.0)$ & $32(11.0)$ & $<0.001$ \\
No & $55(64.0)$ & $260(89.0)$ & \\
Total & $86(100)$ & $292(100)$ & \\
\hline
\end{tabular}

laxity was also significantly lower $(\mathrm{P}<0.05)$. However, there was no significant relationship between the prevalence of generalized ligamentous laxity and ethnicity (Table 6).

More than $90 \%$ of the individuals with generalized ligamentous laxity were unaware of their problem and its importance in choosing an appropriate physical and sports activity. $45.3 \%$ of them did regular physical and sports activities; $14 \%$ had a history of sports injuries, and
Table 6

The prevalence of generalized ligamentous laxity in terms of gender, age and ethnicity.

\begin{tabular}{|c|c|c|c|c|c|}
\hline \multicolumn{2}{|l|}{ Variables } & \multicolumn{3}{|c|}{ Presence of ligamentous laxity } & \multirow[t]{2}{*}{ Significance } \\
\hline & & Yes $(\%)$ & No (\%) & Total & \\
\hline \multirow[t]{2}{*}{ Gender } & Female & $57(31.5)$ & $124(68.5)$ & 181 & $x^{2}=15.09$ \\
\hline & Male & $29(14.7)$ & $168(85.3)$ & 197 & $\begin{array}{l}\mathrm{df}=1 \\
\mathrm{P}<0.001\end{array}$ \\
\hline \multicolumn{2}{|c|}{ Mean of age (years old) } & $21.5(4.43)$ & $26.46(8.23)$ & & $\begin{array}{l}t=5.36 \\
d f=376 \\
P<0.001\end{array}$ \\
\hline \multirow[t]{4}{*}{ Ethnicity } & Persian & $31(30.7)$ & $70(69.3)$ & 101 & $x^{2}=6.31$ \\
\hline & Azeri & $74(76.3)$ & $23(23.7)$ & 97 & $\mathrm{df}=3$ \\
\hline & Kurdish & $16(16.8)$ & $79(83.2)$ & 95 & $\mathrm{P}=0.098$ \\
\hline & Lur & $16(18.8)$ & $69(81.2)$ & 85 & \\
\hline
\end{tabular}

$36.5 \%$ had a history of musculoskeletal diseases (Table 7).

\section{Discussion}

Our study investigated the epidemiology of generalized ligamentous laxity among adults who live in a northwestern province of Iran. We studied 378 participants, of whom 86 (22.8\%) had generalized ligamentous laxity (Beighton's score of 4 and more). The most common involved ligament was the left thump. There was no significant relationship between the prevalence of generalized ligamentous laxity and ethnicity. However, the prevalence of generalized ligamentous laxity was significantly higher in women than in men. It was more common in younger compared to older age groups. The frequency of musculoskeletal diseases was significantly higher in people with generalized ligamentous laxity than the non-affected individuals.

Based on previous studies, the incidence of ligamentous laxity is $4 \%-13 \%$ in a population without any associated systemic and rheumatologic diseases. ${ }^{11,12}$ It is $66.6 \%$ in adolescents with idiopathic scoliosis. $^{16}$

In a study, Jamshidi and colleagues investigated the prevalence of joint hypermobility syndrome on 1005 students aged six to 19 years old in Tehran. They were diagnosed according to Wilkinson and Beighton's criteria (Score $>5$ ). The prevalence of hypermobility syndrome was $23.9 \%$, which was significantly higher in girls (33.7\% of girls compared to $14.1 \%$ of boys). Hypermobility was also more prevalent in the younger age groups. The most commonly involved joints were thumbs, elbows, knees, and fingers, respectively. ${ }^{17}$ Our results are in accordance with theirs in the frequency of joint hypermobility distribution according to age, sex and the most commonly affected joint.

In 2011, Clinch and colleagues studied 6022 adolescents in the United Kingdom. They were diagnosed with having a score of 4 and more according to Beighton's criteria; $23.5 \%$ of girls and $10.6 \%$ of boys had joint hypermobility. ${ }^{18}$ Our results are consistent with this study since the prevalence of generalized ligamentous laxity was significantly higher in women. Chahal and colleague showed that the frequency of generalized ligamentous laxity was higher in the group with primary traumatic anterior shoulder dislocation compared to their other study group. $^{19}$

In another study using the Beighton's criteria, Ramesh and colleagues reported that $42.6 \%$ of their patients with anterior cruciate ligament injuries had generalized ligamentous laxity while this was $21.5 \%$ in their control group. They concluded that there was an internal relationship between proprioception, increasing ligamentous laxity and joint injuries. ${ }^{13}$ In an investigation on the likelihood of an increase in musculoskeletal injuries in patients with generalized ligamentous laxity, Bin Abd-Razak and colleagues compared 100 military personnel aged between 18 and 25 years old with musculoskeletal injuries with 100 individuals without any musculoskeletal injuries or complaint. The generalized ligamentous laxity was observed in $12 \%$ of the first and $4 \%$ 
Table 7

The frequency of knowledge and activities in those who had ligamentous laxity.

\begin{tabular}{|c|c|c|c|}
\hline Knowledge or activity & Yes $(\%)$ & No $(\%)$ & Total (\%) \\
\hline Knowledge about ligamentous laxity in general & $8(9.3)$ & $78(90.7)$ & $86(100)$ \\
\hline Knowledge about the importance of ligamentous laxity in choosing sports activities & $3(3.5)$ & $83(96.5)$ & $86(100)$ \\
\hline Having a history of sports injuries & $12(14)$ & $74(86)$ & $86(100)$ \\
\hline Doing regular physical and sports activities & $29(45.3)$ & $57(54.7)$ & $86(100)$ \\
\hline Having a history of musculoskeletal disorders & $31(36.05)$ & $55(63.95)$ & $86(100)$ \\
\hline
\end{tabular}

of the second group. Their study showed that presence of generalized ligamentous laxity in people with musculoskeletal injuries is probably a contributing factor to those injuries. ${ }^{20}$ Also, Okamura and colleagues found a significant relationship between low back pain and generalized ligamentous laxity in 192 men who were ice skating athletes in Japan. ${ }^{21}$ Our reults are consistent with these studies since the prevalence of musculoskeletal injuries was significantly higher in those who had generalized ligamentous laxity.

Tobias and colleagues studied 2901 adolescents with an average age of 13.8 years old. They considered generalized ligamentous laxity as having Beighton's score of six and more. They found $4.6 \%$ prevalence for this problem. Musculoskeletal pain, particularly in the waist, shoulder, knee, neck, and ankle, was common in the affected individuals. They reported that generalized ligamentous laxity could be a risk factor for musculoskeletal pain during puberty, especially in the shoulders, knees, and ankles. ${ }^{22}$ In a study on 118 athletes, Saremi and colleagues compared 43 athletes suffering from ligamentous laxity with 75 non-affected individuals. Their results showed that athletes with ligamentous laxity have significantly more pain in the shoulders, chronic shoulder injuries, and instability compared to non-affected individuals. ${ }^{15}$ Our reults are again consistent with these studies. This shows that sports injuries and the musculoskeletal disorders are relatively higher in individuals with generalized ligamentous laxity.

In a study by Shakeri and colleagues on 50 student girls of a university in Tehran, there was a significant correlation between the general hypermobility of the body and lower arched feet. ${ }^{23}$ According to some reports, the incidence of ligamentous laxity is more common in some races. ${ }^{24,25}$ Some researchers believe that genetic factors contribute to the onset of this disorder with an impact on connective tissues, but in most cases, it occurs independently of the genetic effect. ${ }^{1}$ In our study, there was no significant relationship between the studied ethnic groups and prevalence of ligamentous laxity.

This report is based on a pilot study for a future national study on generalized ligamentous laxity in Iran. The national study will consider the appropriate sports activities and diversity of ethnic groups in Iran in evaluating the epidemiology of ligamentous laxity with the help of several medical universities. Results of this pilot study could be useful for the national study to make it more accurate to determine the possible number of participants for each ethnic group.

\subsection{Limitations}

All authors participated in examination of the participants and were trained by the first author. Although we expected very little difference in the reliability of examinations, it can still be a possible limitation. Also, when we considered a participant within an ethnic group according to the ethnicity of the parents (that is where s/he and his/her parents were born), there may still be a person in his predecessors (grandmother or grandfather) who is from another ethnic group that we are not aware of. Thus, a person's true ethnicity might not be completely of the ethnic group in which we have grouped him/her. Sample size can be another limitation of our study since it will not possible to know the exact population of each ethnic group in the country. This is classified social security information which cannot be accessed.

\section{Conclusion}

The prevalence of general ligamentous laxity is relatively high among the population aged 17 to 40 in Hamadan province, especially in women, regardless of ethnicity. Most people are unaware of their problem and its importance in choosing the appropriate physical and sports activities. The history of musculoskeletal disorders is significantly higher in the affected compared to non-affected individuals.

Regarding the relatively high prevalence of general ligamentous laxity in the studied population, doing a comprehensive screening at an early age is suggested so that the affected people would try to prevent musculoskeletal injuries associated with ligamentous laxity by strengthening their muscles with exercises or avoiding activities that have a higher chance of causing an injury in them. Also, educating the affected individuals about its importance in selecting the right physical activities is necessary.

\section{Funding}

None.

\section{Declaration of competing interest}

None.

\section{Acknowledgment}

The authors thank Muhammed Hussein Mousavinasab for editing this text. They would also thank Abbas Moradi for doing the statistical analyses of this research.

\section{References}

1. Bird HA. Joint hypermobility in children. Rheumatology. 2005;44(6):703-704.

2. Juul-Kristensen B, Rogind H, Jensen DV, Remvig L. Inter-examiner reproducibility of tests and criteria for generalized joint hypermobility and benign joint hypermobility syndrome. Rheumatology. 2007;46(12):1835-1841.

3. Carter C, Wilkinson J. Persistent joint laxity and congenital dislocation of the hip. Bone Joint Lett J. 1964;46(1):40-45.

4. Decoster LC, Vailas JC, Lindsay RH, Williams GR. Prevalence and features of joint hypermobility among adolescent athletes. Arch Pediatr Adolesc Med. 1997;151(10):989-992.

5. Eccles J, Tung J, Harrison N, Mathias C, Critchley H. Joint hypermobility syndrome and anxiety disorder: structural brain correlates. Eur Psychiatry. 2017:41:S233-S234.

6. Beighton P, Solomon L, Soskolne C. Articular mobility in an African population. Ann Rheum Dis. 1973;32(5):413.

7. Birrell F, Adebajo A, Hazleman B, Silman A. High prevalence of joint laxity in West Africans. Rheumatology. 1994;33(1):56-59.

8. Hakim A, Grahame R. Joint hypermobility. Best Pract Res Clin Rheumatol. 2003;17(6):989-1004.

9. Simpson MR. Benign joint hypermobility syndrome: evaluation, diagnosis, and management. J Am Osteopath Assoc. 2006;106(9):531-536.

10. Neumann DA. Kinesiology of the Musculoskeletal System: Foundations for Rehabilitation. second ed. New York: Mosby; 2013.

11. Biro F, Gewanter HL, Baum J. The hypermobility syndrome. Pediatrics. 1983;72(5):701-706

12. Seckin U, Tur BS, Yilmaz O, Yagci I, Bodur H, Arasil T. The prevalence of joint hypermobility among high school students. Rheumatol Int. 2005;25(4):260-263.

13. Ramesh R, Von Arx O, Azzopardi T, Schranz PJ. The risk of anterior cruciate ligament rupture with generalized joint laxity. J Bone Joint Surg Br. 2005;87(6):800-803.

14. Soderman K, Alfredson H, Pietila T, Werner S. Risk factors for leg injuries in female soccer players: a prospective investigation during one out-door season. Knee Surg 
Sport Traumatol Arthrosc. 2001;9(5):313-321.

15. Saremi H, Yavarikia A, Jafari N. Generalized ligamentous laxity: an important predisposing factor for shoulder injuries in athletes. Iran Red Crescent Med J.

2016;18(6):e38903

16. Ghayem-Hasankhani E, Omidi-Kashani F. Generalized ligamentous laxity; a parameter should not be forgotten in preoperative planning of adolescent idiopathic scoliosis. Iran Red Crescent Med J. 2012 Nov;14(11):702-704.

17. Jamshidi A, Shaeri H, Akbarian M. Prevalence and features of joint hypermobility among school children in Tehran. Biol. 1997:73(2):189-192.

18. Clinch J, Deere K, Sayers A, et al. Epidemiology of generalized joint laxity (hypermobility) in fourteen-year-old children from the UK: a population-based evaluation. Arthritis Rheumatol. 2011 Sep;63(9):2819-2827.

19. Chahal J, Leiter J, McKee MD, Whelan DB. Generalized ligamentous laxity as a predisposing factor for primary traumatic anterior shoulder dislocation. J Shoulder Elb Surg. 2010 Dec;19(8):1238-1242
20. Bin Abd Razak HR, Bin Ali N, Howe TS. Generalized ligamentous laxity may be a predisposing factor for musculoskeletal injuries. J Sci Med Sport. 2014 Sep;17(5):474-478.

21. Okamura S, Wada N, Tazawa M, et al. Injuries and disorders among young ice skaters: relationship with generalized joint laxity and tightness. Open Access J Sport Med. 2014;5:191-195.

22. Tobias JH, Deere K, Palmer S, Clark EM, Clinch J. Joint hypermobility is a risk factor for musculoskeletal pain during adolescence: findings of a prospective cohort study. Arthritis Rheum. 2013 Apr;65(4):1107-1115.

23. Shakeri H, Ahi S, Arab A. The relationship between general hypermobility and foot arch in healthy adult females. Phys Treat. 2012;2(1):51-56.

24. Everman DB, Robin NH. Hypermobility syndrome. Pediatrics in the review. 1998 Apr;19(4):111-117.

25. Larsson LG, Baum J, Mudholkar GS, Kollia GD. Benefits and disadvantages of joint hypermobility among musicians. N Engl J Med. 1993 Oct 7;329(15):1079-1082 